\title{
Investigating the Role of Governmental Factors Affecting Social Capital (Case Study: Iraqi Kurdistan)
}

\author{
Chiman Khayati \\ Graduated Master of Management, Islamic Azad University, Iran \\ Chiman. Khayati@gmail.com
}

\begin{abstract}
Social capital is a latent wealth and property arising from a society's members' mental and psychological readiness to give up personal interests and engage in collective action. Social capital is a form of capital that potentially exists in all human societies. For flourishing and actualizing social capital, factors must be transformed, and special conditions must be satisfied that are seldom and difficult to meet. This study aimed to investigate the factors affecting the strengthening of social capital through the role of government. The study was applied research, and in terms of data collection method, it was a descriptive correlational study. The statistical population of the study was the citizens of Iraqi Kurdistan in 2020. One thousand subjects were selected using the convenience sampling method. The data collection tool was a researcher-made questionnaire. Content validity and measurement model results were used to evaluate the validity and reliability of measurement tools. The questionnaires' validity and reliability results were confirmed. Structural equation modeling through Smart PLS 3 was used for data analysis. The hypothesis testing results showed that the economy, geography and environment, and culture and society would strengthen social capital through government. According to the value obtained for the model fit index, 0.54, the overall model's goodness of fit was confirmed.
\end{abstract}

Keywords: economy, geography and environment, culture and society, government, social capital

\section{Introduction}

Social capital (SC), one of the key concepts of social sciences and constituting one of the cultural foundations of modern societies, together with elements such as rationality and the rule of law, has a special place among social science scholars. In other words, SC as the essence and foundation of modern society prevents the social fragmentation, alienation, and the increasing growth of social deviations through communication and trust in communication networks in the modern individualistic society and facilitates community action by communicating between individuals (Salehi Amiri, 2015). In general, SC is a collective concept that arises from individual behaviors, attitudes, and talents (Ghaffari, 2013).

The SC is a latent wealth and property arising from a society's members' mental and psychological readiness to give up personal interests and engage in collective action. It is a form 
of capital that potentially exists in all human societies. For SC to be flourished and actualized, factors must be transformed, and special conditions must be satisfied that are seldom and difficult to meet (Mojibi, 2013).

In recent years, the SC has become a very important concept and politicians' and political elites' daily slogan. This term is a multifaceted concept in the social sciences influential in many social areas and has found a special place in the literature related to development (Majedi and Lahsaeizadeh, 2006: 92).

According to the World Bank, the SC refers to the norms and networks that are capable of collective action, including the institutions that shape the relationships, customs, quality, and quantity of social interaction in a society. Thus, the SC is not just a set of institutions that have shaped society, but it is like glue that holds those institutions together (World Bank, 1999). Coleman (1990) considers SC as a combination of social structures that facilitate certain actors' actions within these structures. According to Paxton (1999), SC consists of two measurable components: objective associations and subjective ties between individuals. Objective associations connect people in a social context, and subjective ties lead to relationships based on society members' mutual trust and positive emotional relationships. According to Fukuyama (1995), SC is a set of norms in social systems that increases community members' level of cooperation and lowers exchange and communication costs.

Putnam et al. state that "SC refers to a set of social organization features and concepts, such as trust, norms, and networks that can improve the efficiency of society by facilitating coordinated actions' and leads community members to achieve valuable goals (Putnam et al., 1993). Therefore, understanding SC can help communities expand SC dimensions and increase individuals' social, cultural, and economic performance in societies. Suppose development is meant to improve living standards and the continuous improvement of society and the social system towards a better and more humane life. What factors can drive this desire in a national unit? The answer to this question has shaped the rich and extensive literature (Amani Kalarijani, 2010). Although in the traditional views of development management, economic, physical, and workforce capital played a key role, SC's emphasis is on further development in the present era. In the absence of SC, other capitals lose their effectiveness, and the gateways of cultural and economic development become uneven and difficult.

According to Aldridge, Halpem, and Fitzpatrick (2002), intra-group SC exists between closely related people, including family members, close friends, and neighbors. Nevertheless, intergroup social capital is prevalent among individuals with less friendly relationships and commonalities, such as social and political groups. According to Hitt (2002), structural SC facilitates collective action through established rules, and social media is complementary to legal and judicial rules and procedures in this regard. According to Krishna and Uphoff (2002), cognitive SC includes common norms, values, tendencies, and beliefs that lead individuals to mutually beneficial activities.

In this regard, several studies have been conducted, the results of which indicate that as SC declines and weakens, urban society has faced numerous problems: "increased social risks, declined trust, 


\section{Technium Sustainability}

reduced participation, and a serious crisis of social cohesion" (Forrest \& Kearns, 2001), "increased social unrest, violence, anonymity, alienation, social anomalies and indifference, crime and even suicide, and reluctance to participate" (Barliana et al., 2014:180; Cohen \& Prusakstate, 2001:4), "erosion of shared identity" (Castells, 1997), "increasing inequality and inadequate access to health care" (CoE, 2008), and "increasing social harm, anti-social behavior, sabotage, racism, family breakdown, educational failure, and weakening local communities" (Social Exclusion Unit, 1998: 74). In contrast, the factors resulting from the existence of a favorable situation of social capital in urban communities are: "increased citizens' access to services and facilities" (Kawachi,et al , 1999; Sampson,et al, 1997; Cernea, 1993) , "reduced crime" (Kennedy, et al, 1998; Kawachi, et al, 1999b; Putnam, 2000), "reduced violence" (Kennedy,et al, 1998), "increased social control and reduced anti-social and immoral behaviors" (Subramanian, et al., 2002), "increased material and spiritual support" (Wilkinson, 1996), "enhanced self-esteem and mutual respect" (Wilkinson, 1996; Kawachi, et al.,1999a), "rapid transfer of information and strengthening social health" (Lindstro,et al., 2001; Lindstro,et al.,2002; Lindstro,et al., 2002) "reduced mortality and suicide" (Kawachi, etal., 1996, 1997), "increased citizens' participation" (Cummins,et al.,2005,Stafford,2005), "growing per capita public spaces and per capita number of voluntary organizations" (Veenstra, 2005), "expanding social norms, increasing public awareness and participation, and creating common interests among citizens" (Osolen\&Lister,2004:1), "strengthening collective spirit and social stability" (Social Exclusion Unit, 2000:24), "building trust and networks of mutual production and the possibility of collective action" (Fallov, 2011:7), "mobilizing resources to strengthen society" (Social Exclusion Unit, 1998:74), and "establishing a moral society with an emphasis on social cohesion" (Taylor,2004). Thus, according to studies, the consideration of SC "has led to a wide range of desirable outcomes on a social scale and will reflect the ability of community members to cooperate, organize, and interact with each other" (Hughes\&Stone,2002).

This issue has been emphasized more than ever by considering the concept of "social capital" as a clear and effective vision for the public interest (Bourdieu, 1980, 1983/1986; Coleman, 1988, 1990; Lin, 1982, 1997, 2001a). A wide range of experts now believes that "many problems in the process of public life are due to the consequences of weakening SC in urban society" (Barliana et al.,2014: 180). They argue that societies currently have very little SC and suffer from it (Krivo \& Peterson, 1996; Krivo et al., 1998; Marks, 1991; Morenoff et al., 2001; Perkins \& Taylor, 1996; Peterson \& Krivo, 2005; Sampson et al., 1997; Steptoe\& Feldman, 2001; Wilson, 1987, 1996; Wilson \& Aponte, 1985).

Most studies on SC are declining, and they indicate a poor state of SC in recent years (Tajbakhsh et al., 2003; Abdollahi and Mousavi, 2007; Saadat, 2008; Shiani et al., 2009; Sadeghi Shahedani and Maghsoudi, 2010; Motavasseli et al., 2011; Amini Rarani et al., 2011, Hosseinizadeh and Niko Nasbati, 2012, Behboodi et al., 2013, Pakseresht, 2014; Bastani and Razmi, 2014; Rad \& Fathi, 2014; Karimi Rahjerdi et al., 2014). The trend of SC developments is considered one of the controversial issues of development due to its economic, social, and political structure. Studies in this field have emphasized the role of several factors, including demographic changes, revolution, and war, in the formation of these developments. In this study, the factors affecting the formation of SC are analyzed. 


\section{Theoretical foundations and literature review Factors affecting social capital}

Several factors are involved in the formation and evolution of the SC structure. Numerous studies have been conducted in the SC literature, and various factors have been considered, which can be mainly classified as follows:

A. Social and cultural factors: Personality traits, including age, gender, education, and other personal characteristics, are significantly related to SC. Social participation and socialization are different in different age groups, so that there is an inverse relationship between age and social participation. Men's formal participation in social activities is higher than women's due to their greater labor market participation. There is also a positive relationship between school years and SC (Offe and Fuchs, 2002). Household characteristics, including household size, employment status, type of residential homeownership, and family involvement, are also related to SC. Job-status as a representative of job security, income, and leisure has a significant relationship with SC, and employees have more associative and participatory activities than the unemployed (Ibid). In families that resolve social problems with others' help and have active social participation, people have a greater share and participation in SC (Krishna and Uphoff,2002).

In addition to the above, Characteristics of social structure, such as generational change, ethnic and linguistic homogeneity, social stability, shared values, religion, social security, ideology, and the like, are also important in shaping SC. What has happened to a generation (such as war, recession, rising divorce rates, and the replacement of new civilizations) is directly related to that generation's SC (Putnam, 2000). There is also a positive relationship between religiosity and religious commitment and SC because religious ceremonies and rituals increase people's participation, develop cooperation, and familiarize them with social issues (Offe and Fuchs, 2002). The disintegration of social organization or social relations can be very destructive to SC. Ideology can also create SC by imposing this desire on people to act for the benefit of something or someone other than themselves. Of course, there are ways in which ideology can negatively affect SC. An ideology of self-sufficiency, such as that believed by Epicurus' followers in ancient Greece, or an ideology that emphasizes the individual and independent relationship of each individual with God, which is largely the basis of Protestantism, can prevent the creation of SC.

B. Economic and material factors: Income, income distribution, inflation, employment, access to media and press, access to education, travel expenses, etc., affect the SC. There are two views on the impact of income levels on SC. The first view is that people with higher incomes are more familiar with associative and participatory activities and their benefits, which encourages them to participate more and, consequently, strengthens the SC. The opposite view states that people with higher incomes increase the opportunity cost; therefore, increased participation is conditional on high participation benefits and compensation for this cost. Besides, with money, people with higher incomes can easily get what is achieved through participatory activity (Brehm and Rahn ,1997 ;Pargal and Gilligan, 2002). Less SC is also generated when people need each other less because of 
prosperity and abundance, government assistance, or other factors (Coleman, 1998). The press's availability and mass media use also increase people's awareness and sensitivity to social issues. Also, income inequality and rising unemployment reduce trust, and economic pressures cause people to view them as rivals rather than peers in their interactions with others. Therefore, increasing the income gap and unemployment will lead to a weakening of SC (ibid). Inflation, as one of the manifestations of economic stability, affects SC in various ways.

C. On the one hand, inflation affects the power and quality of people's participation in social affairs by influencing their real wealth and purchasing power. On the other hand, as inflation widens the income and wealth gap between rich and poor, the SC weakens. Inflation can also determine the extent of people's trust in the government and its policies so that higher inflation will lead to more people's distrust in the government.

D. Geographical and environmental factors: Migration rate, rural or urban area, an industrial or agricultural area, socio-economic advantages in the area, number of residents in the area, the composition of owners and non-owners, neighborhood age, etc., affect the SC structure. Prolonged residence in an area strengthens cooperation and partnership. Residential home ownership also strengthens individuals' sense of belonging to their place of residence and more compliance with the norms and customs prevailing in the area (Putnam, 2000; Pargal and Gilligan, 2002). The changed urbanization ratio can lead to a change in SC's composition from an intragroup and intergroup perspective. Increasing this ratio strengthens intergroup SC, and decreasing

it increases intragroup SC. According to Putnam studies, suburbanization, marginalization, and urban sprawl are among the factors weakening SC's level. These factors may lead to the formation of criminal groups and networks in society; in other words, they are a source of negative SC.

E. The role of government in strengthening social capital: According to Fukuyama (1997), the government can play a significant role in transforming, shaping, and strengthening the structure of SC. He specifically outlines four tasks for the government to strengthen SC: (1) providing grounds for the formation of civic institutions; (2) improving and expanding public education; (3) securing citizens for voluntary participation in social institutions; (4) refraining from the takeover of various economic, cultural, and social sectors and assigning related activities to public institutions to engage them in the activities and paving the way for the establishment and strengthening of institutions and social networks between different groups of the people. According to Putnam (1993), how the government behaves can also significantly impact changes in SC. He argues that a transparency approach in democratic governments and societies raises SC's level, while the conservative trend weakens SC. In other words, the more the government seeks to clarify the environment governing the society and its plans and actions, the more it can attract trust and participation. The more secrecy and conservatism exist in government plans, the fewer people trust the government and its policies.

\section{Method}

The present study is applied research regarding purpose, the data collection is a quantitative survey approach, and the research method is descriptive and correlational. 


\section{Technium Sustainability}

\section{Population}

The statistical population is the main population under study. The population is all members to whom we are interested in generalizing the research findings (Delavar, 1995, p. 147). The statistical population of this study consists of citizens living in Iraqi Kurdistan.

\section{Determination of sample size for partial least squares structural equation modeling (PLS-SEM)}

Since the analysis method selected for the research hypotheses is structural equation modeling, there are two approaches to structural equations. A covariance-based approach can be performed using AMOS and LISREL software. This approach requires respondents to be at least five times the number of the questionnaire items, and the questionnaire must be completed.

Another approach is variance-based structural equations, which can be done using Smart Pls software. In this approach, the thumb rule is used to determine the sample size as follows. One of the known rules for determining the minimum sample required in Smart Pls is provided by Barkelay et al. (1995). The authors stated that the minimum sample size required to use the Smart Pls method was equal to the maximum value obtained from the following two rules:

1) Ten multiplied by the number of measurement model criteria with the maximum criteria among the study's main model's measurement models.

2) Ten multiplied by maximum relationships in the structural part of the main research model

related to one variable (Davari and Rezazadeh, 2014)

According to the above two rules, the minimum sample size is 150 , but for generalizing the partial model results, the sample size was 250 . In this study, a multi-stage cluster sampling method is used. Comprehensive sampling is not possible due to the large population size, dispersion, time-consuming, and the possibility of increasing the error rate. It is better to use the multi-stage cluster sampling method (Khaki, 2008).

\section{Data collection tools}

In this study, library sources, articles, relevant books, and the World Wide Web (internal and external research) are used to collect data related to the theoretical foundations and literature review. Since the most common data collection tool in survey research is a questionnaire, this study uses a researchermade questionnaire. Respondents' views are collected on a five-point Likert scale. In this method, respondents are asked to express their agreement or disagreement with a proposition or importance given to a factor using a standard set of responses.

Table 1: Main criteria, dispersion, and distribution of factors

\begin{tabular}{|l|c|c|c|c|c|}
\hline & Economy & Geography and environment & Government & SC & $\begin{array}{l}\text { Society and } \\
\text { culture }\end{array}$ \\
\hline Mean & 3.3167 & 3.2324 & 3.2528 & 3.0944 & 3.2213 \\
\hline Std. Deviation (SD) & .78597 & 1.01082 & 1.04399 & 1.05775 & .98942 \\
\hline Variance & .618 & 1.022 & 1.090 & 1.119 & .979 \\
\hline Skewness & -.064 & -.123 & -.116 & -.281 & -.151 \\
\hline Kurtosis & -.413 & -.894 & -.931 & -.955 & -.645 \\
\hline
\end{tabular}


Table 1 presents some of the descriptive statistics concepts, including mean, standard deviation, variance, skewness, and kurtosis. Central parameters are a set of parameters that describe a statistical distribution that expresses the data's characteristics relative to the distribution center. Mean as a point of equilibrium and center of gravity of a statistical distribution is one of the main indicators suitable for showing data centrality. For example, the mean of "economy" is 3.31, which indicates that most of the data is centered on this point.

Another category of parameters describing the population is dispersion parameters. Dispersion parameters are a benchmark for determining the degree of data dispersion from each other or their degree of dispersion relative to the mean. The standard deviation (SD) is one of the most important dispersion parameters. The high standard deviation of a statistical distribution indicates that the data are more dispersed. Among the variables of this study, "social capital" with 1.057 has the highest dispersion. The skewness indicates the asymmetry of the frequency curve. If the skewness coefficient is zero, the population is perfectly symmetric. If this coefficient is positive, there is skewness to the right, and if the coefficient is negative, there is skewness to the left. In general, if the skewness and kurtosis are not within the range $(2,-2)$, the data are very far from the normal distribution. (Of course, some statisticians may consider this range to be smaller or larger). The skewness observed for the studied variables is in the range $(2,-2)$. It means that the research variables are skewed normally, and their distribution is symmetrical. The kurtosis value of the variables is also within the range $(2,-2)$. It indicates that the distribution of variables has normal kurtosis.

\section{Inferential statistical analysis of research data}

\section{Measurement model}

\section{A: $\quad$ Reliability of measuring instruments}

1) Factor loadings of observed variables: According to the researchers, the reflective measurement model will be homogeneous if the absolute value of each observed variable's factor loading corresponding to that hidden variable is at least 0.7 . Therefore, the loadings were examined. Some have suggested removing the observed reflective variable from the measurement model below 0.4 while removing the composite reliability would increase the corresponding reflective measurement model (Hair et al., 2017).

Significance of factor loadings: The results of the significance of (outer) factor loadings are shown in Table 2. If the value obtained is considered above the minimum statistics at the confidence level, that relationship or hypothesis is confirmed. At the significance level of $90 \%, 95 \%$, and $99 \%$, this value is compared with the minimum statistics of $1.64,1.96$, and 2.58, respectively.

Cronbach's alpha and composite reliability: Cronbach's alpha method is used to calculate the internal consistency of measuring instruments, including questionnaires or tests that measure different characteristics. In such tools, the answer to each question can take different numerical values. To calculate Cronbach's alpha, one must first determine the variance of scores in each subset of the questionnaire items and the total variance. 


\section{Technium Sustainability}

The Cronbach's alpha index assumes that each measurement model's observable variables have the same weights, and in fact, their relative importance is assumed to be equal. The measure proposed by Werts et al. (1974) called composite reliability is used to solve this problem. In this measure, since the items' factor loadings are used when calculating, the composite reliability values are shown more and better than Cronbach's alpha.

Table 2: Outer Loadings

\begin{tabular}{|c|c|c|c|c|c|c|c|}
\hline & & Original sample & SD & t-statistics & p-value & $\begin{array}{c}\text { Cronbach } \\
\text { 's alpha }\end{array}$ & $\begin{array}{l}\text { Composite } \\
\text { Reliability }\end{array}$ \\
\hline \multirow{4}{*}{$\begin{array}{l}\text { Society and } \\
\text { culture }\end{array}$} & Q1 & 0.734 & 0.045 & 16.392 & 0.000 & \multirow{4}{*}{0.701} & \multirow{4}{*}{0.811} \\
\hline & $\mathrm{Q} 2$ & 0.675 & 0.045 & 14.842 & 0.000 & & \\
\hline & Q3 & 0.691 & 0.053 & 13.132 & 0.000 & & \\
\hline & $\mathrm{Q} 4$ & 0.774 & 0.027 & 28.698 & 0.000 & & \\
\hline \multirow{4}{*}{ Economy } & Q5 & 0.769 & 0.036 & 21.286 & 0.000 & \multirow{4}{*}{0.875} & \multirow{4}{*}{0.915} \\
\hline & Q6 & 0.859 & 0.023 & 38.116 & 0.000 & & \\
\hline & Q7 & 0.913 & 0.010 & 87.890 & 0.000 & & \\
\hline & Q8 & 0.868 & 0.017 & 50.813 & 0.000 & & \\
\hline \multirow{4}{*}{$\begin{array}{c}\text { Geography and } \\
\text { environment }\end{array}$} & Q9 & 0.877 & 0.014 & 61.065 & 0.000 & \multirow{4}{*}{0.910} & \multirow{4}{*}{0.937} \\
\hline & $\mathrm{Q} 10$ & 0.872 & 0.015 & 56.633 & 0.000 & & \\
\hline & Q11 & 0.898 & 0.016 & 55.093 & 0.000 & & \\
\hline & Q12 & 0.902 & 0.011 & 80.964 & 0.000 & & \\
\hline \multirow{3}{*}{ Government } & Q13 & 0.900 & 0.013 & 68.981 & 0.000 & \multirow{3}{*}{0.867} & \multirow{3}{*}{0.911} \\
\hline & Q14 & 0.881 & 0.017 & 51.312 & 0.000 & & \\
\hline & Q15 & 0.904 & 0.013 & 69.818 & 0.000 & & \\
\hline \multirow{5}{*}{ SC } & Q16 & 0.832 & 0.023 & 36.630 & 0.000 & \multirow{5}{*}{0.902} & \multirow{5}{*}{0.926} \\
\hline & Q17 & 0.891 & 0.015 & 61.013 & 0.000 & & \\
\hline & Q18 & 0.890 & 0.015 & 59.765 & 0.000 & & \\
\hline & Q19 & 0.880 & 0.021 & 41.365 & 0.000 & & \\
\hline & Q20 & 0.751 & 0.035 & 21.522 & 0.000 & & \\
\hline
\end{tabular}

As shown in Table 2, the factor loadings of all items are greater than 0.4. Therefore, the measurement model is homogeneous, and factor loadings are acceptable values.

The significant results of t-statistic values in Table 2 showed that $\mathrm{t}$-statistic values were reported to be greater than 2.58 for all items. It means that the relationship between items and their latent variable is accepted at the 99\% confidence level. In Table 2, the results of Cronbach's alpha coefficients and composite reliability showed that the values of these indices for all latent variables are greater than 0.7. Therefore, the reliability of measuring instruments using these two scales was also confirmed (Henceler et al., 2011; Hair et al., 2017).

\section{B: $\quad$ Validity of measuring instruments}

1) Convergent validity: Convergent validity means measuring the degree of explanation of a latent variable by its observable variables (Barclay et al., 1995). For Average Variance Extracted (AVE), a minimum value of 0.5 is acceptable, indicating that observable variables explain at least $50 \%$ of their latent variable variance. 


\section{Technium Sustainability}

2) Discriminant validity: Discriminant or divergent validity measures a reflective measurement model's ability to differentiate the latent variable observables from other observables in the model. Discriminant validity complements convergent validity, indicating the difference between a latent variable and other indicators in the same structural model.

\section{A) Fornell Larcker Criterion}

According to this criterion, a latent variable should be more scattered among its observables than other latent variables. It can be said that the latent variable has high discriminant validity. Accordingly, the square root of the AVE of any latent variable must be greater than the maximum correlation between that latent variable and other latent variables (Fornell \& Larcker, 1981).

Table 3: Fornell-Larcker Criterion-AVE

\begin{tabular}{|c|c|c|c|c|c|c|}
\hline & Economy & $\begin{array}{l}\text { Geography and } \\
\text { environmen } \\
\text { t }\end{array}$ & Government & SC & Society and culture & AVE \\
\hline Economy & 0.854 & & & & & 0.729 \\
\hline $\begin{array}{ll}\text { Geography } & \text { and } \\
\text { environment } & \\
\end{array}$ & 0.823 & 0.887 & & & & 0.787 \\
\hline Government & 0.852 & 0.849 & 0.849 & & & 0.722 \\
\hline SC & 0.816 & 0.811 & 0.814 & 0.823 & & 0.678 \\
\hline $\begin{array}{l}\text { Society } \\
\text { culture }\end{array}$ & 0.717 & 0.598 & 0.688 & 0.703 & 0.720 & 0.518 \\
\hline
\end{tabular}

As can be seen in Table 3, the AVE values of the latent variables showed that all variables had values greater than 0.5 . Therefore, it can be said that the convergent validity of the measuring instruments was verified using the AVE index.

Based on the results from Table 3, the square root of the AVE of each latent variable is greater than the maximum correlation between that latent variable and other latent variables. Accordingly, the discriminant validity of the measurement model was also confirmed using the Fornell Larcker criterion.

B) Cross loading test: According to this test, it is suggested that the factor loading of each observable variable on its latent variable should be greater than the factor loading of the same observable variable on other latent variables (Hair et al., 2017). 


\section{Technium Sustainability}

Table 4: Cross Loadings

\begin{tabular}{|c|c|c|c|c|c|}
\hline & Economy & $\begin{array}{c}\text { Geography and } \\
\text { environment }\end{array}$ & Government & SC & $\begin{array}{l}\text { Society } \\
\text { and } \\
\text { culture }\end{array}$ \\
\hline $\mathrm{Q} 1$ & 0.533 & 0.393 & 0.465 & 0.447 & 0.734 \\
\hline Q2 & 0.419 & 0.431 & 0.402 & 0.458 & 0.675 \\
\hline Q3 & 0.371 & 0.311 & 0.334 & 0.384 & 0.691 \\
\hline $\mathrm{Q} 4$ & 0.681 & 0.532 & 0.677 & 0.657 & 0.774 \\
\hline Q5 & 0.769 & 0.535 & 0.695 & 0.671 & 0.611 \\
\hline Q6 & 0.859 & 0.653 & 0.646 & 0.647 & 0.605 \\
\hline Q7 & 0.913 & 0.785 & 0.783 & 0.787 & 0.640 \\
\hline Q8 & 0.868 & 0.813 & 0.772 & 0.767 & 0.625 \\
\hline Q9 & 0.756 & 0.877 & 0.761 & 0.763 & 0.518 \\
\hline Q10 & 0.686 & 0.872 & 0.726 & 0.736 & 0.547 \\
\hline
\end{tabular}

\begin{tabular}{|l|r|r|r|r|r|}
\hline Q11 & 0.751 & 0.898 & 0.755 & 0.747 & 0.523 \\
\hline Q12 & 0.727 & 0.902 & 0.771 & 0.775 & 0.536 \\
\hline Q13 & 0.719 & 0.805 & 0.900 & 0.795 & 0.581 \\
\hline Q14 & 0.698 & 0.729 & 0.881 & 0.770 & 0.580 \\
\hline Q15 & 0.718 & 0.793 & 0.904 & 0.792 & 0.573 \\
\hline Q16 & 0.643 & 0.718 & 0.747 & 0.832 & 0.549 \\
\hline Q17 & 0.734 & 0.788 & 0.802 & 0.891 & 0.569 \\
\hline Q18 & 0.699 & 0.745 & 0.757 & 0.890 & 0.573 \\
\hline Q19 & 0.733 & 0.793 & 0.785 & 0.880 & 0.599 \\
\hline Q20 & 0.588 & 0.589 & 0.603 & 0.751 & 0.579 \\
\hline
\end{tabular}




\section{Technium Sustainability}

The difference between the latent variables in the model showed that each item's loading factor on its latent variable was more than the same factor loading of the observable variable on the other latent variables. Accordingly, the discriminant validity of the measuring instruments was confirmed using the cross-loadings.

\section{Structural model testing}

The first-order factor analysis of endogenous and exogenous variables showed that all constructs have the necessary validity and reliability. Therefore, in this section, the conceptual model's overall structure is tested to determine whether the data confirmed the theoretical relationships between the researcher's variables during the conceptual framework development phase. Three issues are considered in this regard:

1. The positive and negative signs of parameters related to communication paths between latent variables indicate whether these parameters confirm the direction's hypothetical relationships.

2. The estimated parameters show the strength of the predicted relationships. Here, the estimated parameters must be significant, i.e., the absolute value of the t-value must be greater than 1.96 .

3. The multiple correlation square $\left(\mathrm{R}^{2}\right)$ shows the variance of each internal (dependent) latent variable explained by the external (independent) latent variables. The higher the value of $\mathrm{R}^{2}$, the higher the strength of variance expression. 


\section{Technium Sustainability}

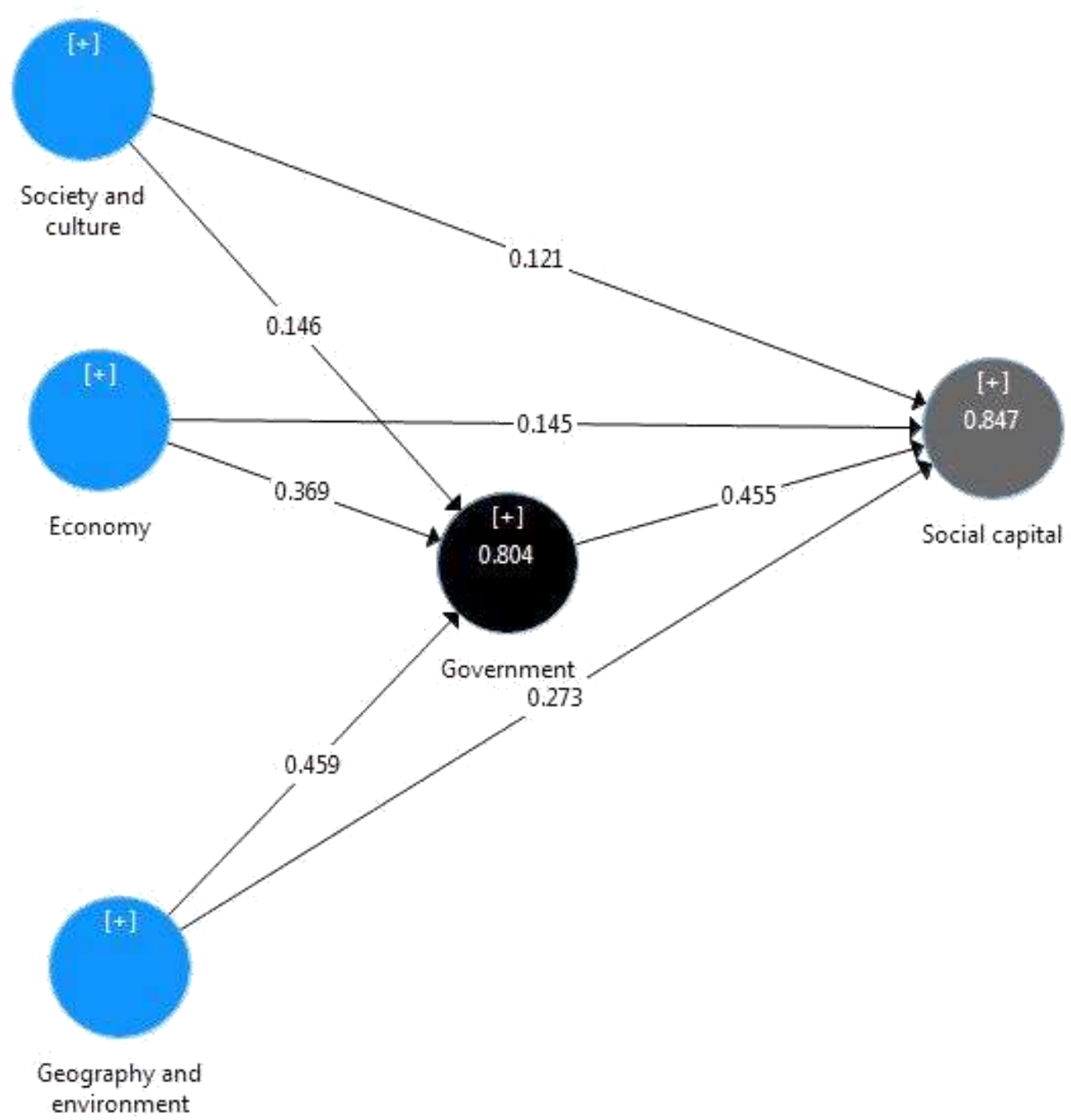

Fig.1. Path coefficient diagram

Fig.1 shows the variables' path coefficient and each independent variable's effect on the dependent variable. The path coefficient values are in the range of -1 and 1 . The higher the positive value, the greater the effect of the independent variable on the dependent variable.

The coefficient of determination ( $\mathrm{R}$-squared or $\mathrm{R}^{2}$ ) indicates the variance explanation of the dependent variable by the independent variables. One of the disadvantages of $\mathrm{R}^{2}$ is that it overestimates the success rate of the model and takes less into account the number of independent variables and the sample size. Therefore, some researchers prefer to use another measure called adjusted $\mathrm{R}$-squared $\left(\mathrm{R}^{2}\right)$ (Sarukhani, 2003). The results of $\mathrm{R}^{2}$ are given in Table 5 .

Table 5: R-squared results

\begin{tabular}{|c|c|c|}
\hline & $\mathbf{R}^{\mathbf{2}}$ & ${\text { Adjusted } \mathbf{R}^{\mathbf{2}}}$ \\
\hline Government & 0.804 & 0.802 \\
\hline SC & 0.847 & 0.845 \\
\hline
\end{tabular}




\section{Technium Sustainability}

Adjusted $\mathrm{R}^{2}$ is 0.847 for SC, which indicates that more than $84 \%$ of SC changes are affected by research variables, and the rest are factors that are not considered in the model.

Another criterion for examining the structural model is the effect size. Cohen (1988) rated 0.02, 0.15 , and 0.35 as weak, medium, and strong values, respectively.

Table 6: f-square

\begin{tabular}{|l|c|c|}
\hline & Government & SC \\
\hline Economy & $\mathbf{0 . 1 6 4}$ & 0.028 \\
\hline Geography and environment & $\mathbf{0 . 3 4 6}$ & 0.117 \\
\hline Government & & $\mathbf{0 . 2 6 5}$ \\
\hline Society and culture & 0.051 & 0.043 \\
\hline
\end{tabular}

The effect size (f-square) (Table 6) showed that this value was reported within the weak and strong range.

Significance of path coefficients $(\beta)$ : One of the measures to confirm the structural model's relations is the path coefficients' significance. The path coefficients' significance is a complement to the magnitude and direction of the model's $\beta$. If the value obtained is considered above the minimum statistics at the confidence level, that relationship or hypothesis is confirmed. At the significance level of $90 \%, 95 \%$, and $99 \%$, this value is compared with the minimum t-statistics of $1.64,1.96$, and 2.58 , respectively.

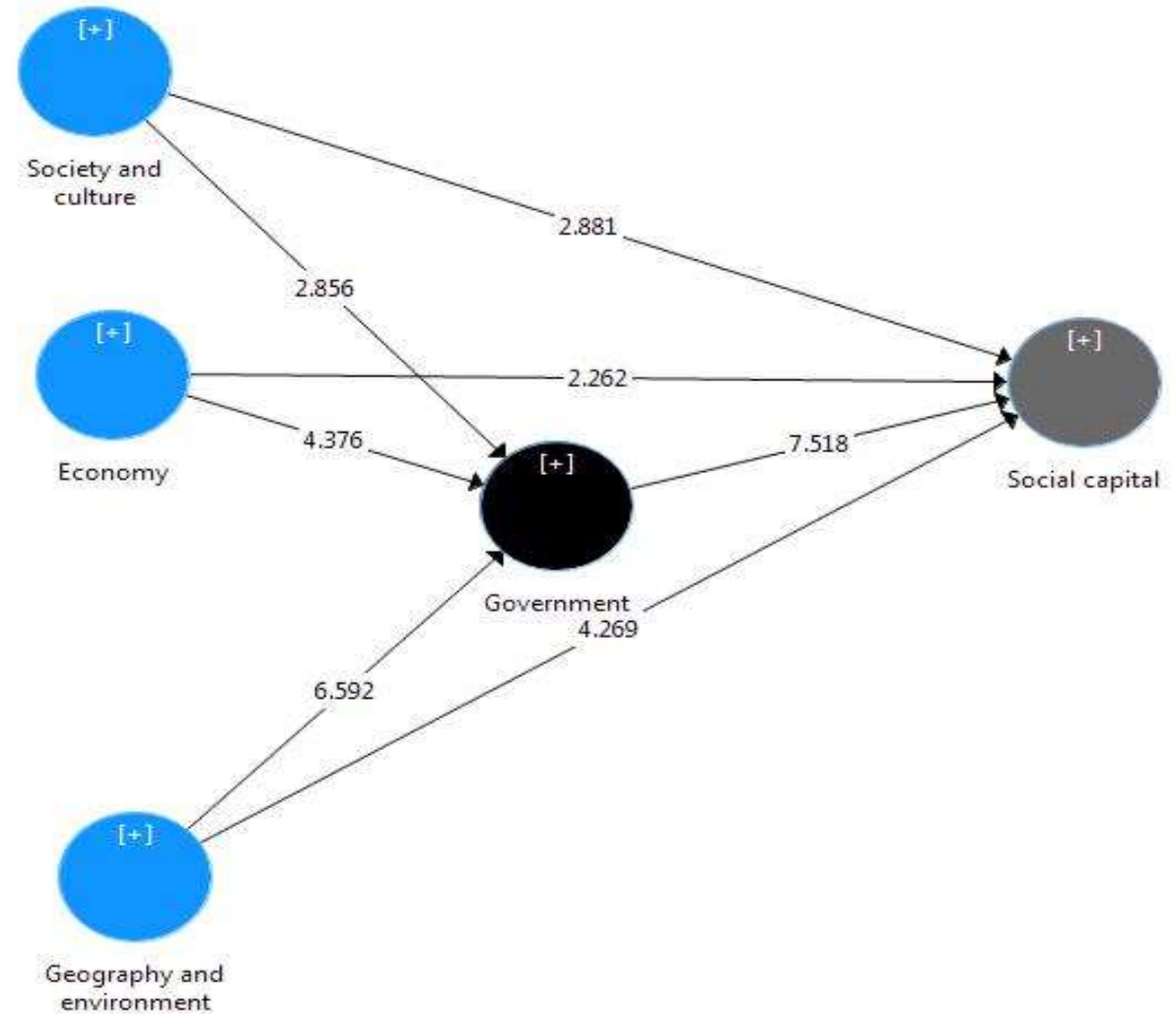

Fig.2. Significance of path coefficients 


\section{Technium Sustainability}

Figure 2 shows the significance of path coefficients. The results obtained from this graph showed that the variables' relationships were reported to be significant at the $95 \%$ confidence level. Model's predictability or cross-validated redundancy (CV Red) is another criterion for examining the structural model. The purpose of this criterion is to investigate the predictability of the structural model by blindfolding. The most well-known criterion for measuring predictability is Q2, according to which the model should predict reflective endogenous latent variable indicators. The values obtained from the test are positive, which indicates the good quality of the structural model (Henseler et al., 2009).

The model's predictive power for latent endogenous variables, $0.02,0.15$, and 0.35 , were introduced as weak, medium, and strong values for this criterion, respectively (Henseler et al., 2009). Table 7 shows that the predictive power of the model is strong.

Table 7: Cross-validated redundancy construct

\begin{tabular}{|l|c|}
\hline & $\mathbf{Q}^{\mathbf{2}}$ (=1-SSE/SSO) \\
\hline Government & 0.539 \\
\hline SC & 0.530 \\
\hline
\end{tabular}

\section{The overall fit of the structural equation modeling}

Models that are examined with a variance-based approach through software such as Smart PLS do not have a general measure to look at the model as a whole. In other words, there is no criterion to measure the whole model, similar to the covariance-based approach. However, various studies in this area suggested the Goodness of Fit (GOF) index proposed by Tenenhaus et al. (2005 that could be used instead of the fit indices found in covariance-based approaches. GOF considers both structural and measurement models together and tests their quality. In this index, the average $\mathrm{R}^{2}$ and average communalities are calculated manually.

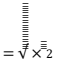

GOF is the square of the multiplication of the average communalities by average ${ }^{2}$. Since this value depends on the two mentioned indices, this index ranges between 0 and 1 . Wetzels et al. (2009) introduced $0.01,0.25$, and 0.36 as weak, medium, and strong values for GOF.

Table 8: GOF

\begin{tabular}{|c|c|c|c|c|c|}
\hline & & $\mathrm{v}$ & Communalities & v & GOF \\
\hline Economy & & \multirow{5}{*}{0.825} & 0.729 & \multirow{5}{*}{0.68} & \multirow{5}{*}{0.561} \\
\hline $\begin{array}{c}\text { Geography and } \\
\text { environment }\end{array}$ & & & 0.787 & & \\
\hline Government & 0.804 & & 0.722 & & \\
\hline SC & 0.847 & & 0.678 & & \\
\hline $\begin{array}{l}\text { Society and } \\
\text { culture }\end{array}$ & & & 0.518 & & \\
\hline
\end{tabular}




\section{Technium Sustainability}

The value obtained for GOF is 0.496 , which is higher than the value proposed by Wetzels et al. (2009), i.e., 0.36, indicating the model's strength. Therefore, the overall model's GOF is validated.

Table 9: Model's fit

\begin{tabular}{|c|c|c|}
\hline & Saturated model & Estimated model \\
\hline SRMR & 0.101 & 0.101 \\
\hline
\end{tabular}

The optimum value for this index is a maximum of 0.08. The results showed that this index was reported to be equal to 0.079 , which is a desirable value. Therefore, the overall model's GOF is approved.

The results showed that the path coefficient of economic factors on government factors is equal to 0.369 . This relationship's t-statistic was significant at a 95\% confidence level ( $\mathrm{p}$-value $\leq$ 0.05). Accordingly, economic factors have a positive and significant effect on government factors.

The results showed that the path coefficient of economic factors on SC is equal to 0.145 . This relationship's t-statistic was significant at a 95\% confidence level ( $p$-value $\leq 0.05$ ). Therefore, economic factors have a positive and significant effect on SC.

Table 10: Hypothesis testing results

\begin{tabular}{|l|c|c|c|c|}
\hline & Original sample (O) & SD & t-statistic $(\mid \mathbf{O} / \mathbf{S D})$ & p-value \\
\hline Economy -> Government & 0.369 & 0.084 & 4.376 & 0.000 \\
\hline Economy -> Social capital & 0.145 & 0.064 & 2.262 & 0.024 \\
\hline Geography and environment -> Government & 0.459 & 0.070 & 6.592 & 0.000 \\
\hline Geography and environment -> Social capital & 0.273 & 0.064 & 4.269 & 0.000 \\
\hline Government -> Social capital & 0.455 & 0.061 & 7.518 & 0.000 \\
\hline Society and culture -> Government & 0.146 & 0.051 & 2.856 & 0.004 \\
\hline Society and culture -> Social capital & 0.121 & 0.042 & 2.881 & 0.004 \\
\hline
\end{tabular}

\section{Conclusion}

According to the results of convergence analysis using the Johansson method, there is a negative relationship between SC and investment, income, and human capital in the long run. At the same time, there is a positive relationship between SC and inequality in income distribution, unemployment, inflation, urbanization, and industrialization. In other words, increased investment can improve SC by strengthening communication platforms in society. Increasing per capita income can also enhance people's affordability to participate in various social affairs and strengthen SC by improving their purchasing power. Besides, investing in human capital can improve SC by increasing public awareness, sensitivity, and social affairs participation.

If income inequality increases and class differences, contradictions, and cynicism arise between different groups, incomes increase, and trust between the society members decreases. Also, due to the increase in inflation, on the one hand, the purchasing power of individuals in society decreases and weakens their participation in social affairs. On the other hand, by weakening economic 
stability, public trust in the government is damaged. Unemployment can have a devastating effect on SC by reducing economic and social participation and paving the way for social crimes and offenses. Due to the lack of institutionalized urban culture and the prevalence of marginalization at the beginning of urbanization, the ground was prepared for many events incompatible with SC.

However, in the long run, with the institutionalization of urban culture and the formation of regulatory institutions for collective activities, we can see an improvement in SC.

According to the error correction model, as in the long run, in the short run, variables such as investment, per capita income, and human capital also have a positive and significant effect on the formation and accumulation of SC. Unlike the long run, inflation and income inequality have little effect on SC changes in the short run. Declining social security, intensifying unemployment, urbanization, and industrialization in the short term also weaken SC.

\section{References}

[1] Abdollahi M, Mosavi M. [Social and economic capital of Iran the current status prospects and the possibility of transition]. SWQ. 2007;6(25):195-233.

[2] Bullen P. Social Capital [May 24, 2016]. Available from: http://www.mapl/pdf/scquest.pdf.

[3] Capital in development, edited by Thierry Van Bastelaer, Melbourne, Cambridge University Press.

[4] Coleman, J. (1990). Foundations of Social Theory, Cambridge, Harvard University Press.

[5] Elmi Z, Sharehpour M, Hosseini A. [Social capital and how it affects the economy]. JFER. 2005;71:239-96.

[6] Emamjome J, Rahbar ghazi M, Esanejad O, Marandi Z. [Investigating the Relationship Between Social

[7] Capital and Political Participation among Students of Isfahan University]. IPSA. 2012;7(4):7-34.

[8] Foladiyan A. [Studying the amount of social capital among Islamic Azad University students of Mashhad].

[9] QJJHC. 2009;6(21):87-112.

[10] Fukuyama, F. (1995). Trust: The Social Virtues and the Creation of Prosperity, New York, Free Press. Ghaffari M, Khani L. [The Relationship between Social Capital and Cultural Intelligence with Medical

[11] Students'Academic Performance]. IJME. 2013;13(8):642-51.

[12] Gharibi H, Gholizade Z, Gharibi J. [Predicting Socal capital of Students Based on Background Variables].

[13] JEMR. 2010;2(2):54-135.

[14] Ghiyasi Nadoshan S, Aminolroaya A. [Investigating the Impact of the Dimensions of Social Capital and Intellectual Capital on the Rate Human resource productivity]. MSDE. 2016;25(80):183-209.

[15] Hitt, M. A., L. Ho-Uk and E. Yucel (2002). "The Importance of Social Capital to the Management of Multinational Enterprises: Relational Networks among Asian and Western Firms," Asia Pacific Journal of Management, 19.

[16] Kiamarsi A, Momeni S. [A survey of the relationship between social capital and happiness and academic achievement in female students]. JSP. 2013;2(1):119-30.

[17] Krishna, A. and N. Uphoff (2002). "Mapping and Measuring Social Capital Through Assessment of Collective Action to Conserve and Develop Watersheds in Rajasthan, India." PP. 85 - 88, 115 - 124 in The Role of Social

[18] Mojibi T, Nabavi F. [The Relationship between Social Capital and Social Responsibility]. 2013;11(36):31-41. 


\section{Technium Sustainability}

[19] Mooghali A, Bahmanyari H, Daneshvar B, Masoumi R. [The Relationship between Social Capital and Knowledge Management among Staff Personnel of Shiraz University of Medical Sciences]. Med J. 2015;6(2):40-50.

[20] Moradian Sorkhkalaee M, Eftekhar Ardebili H, Nejat S, Saiepour N. [Social Capital among Tehran University Of Medical Sciences Students]. JHS. 2012;10(20):19-30.

[21] Nateghpour M, Firouz Abadi SA. [Social Capital and Factors affecting its formation in Tehran]. IJS.

[22] 2005;6(4):59-91.

[23] Offe, C. and S. Fuchs (2002). "A Decline of Social Capital? The German Case", in Putnam (ed.), Democracies in Flux: The Evolution of Social Capital in Contemporary Society, New York, Oxford University Press.

[24] Onyx J, Bullen P. Measuring social capital in five communities. J Appli Behav Sci. 2000;36(1):23-42.

[25] Pargal, S. and D. Gilligan (2002). "Private Provision of a Public Good: Social Capital and Solid Waste Management in Dhaka," Bangladesh. www.wds.worldbank.org.

[26] Paxton, P. (1999). "Is Social Capital Declining in the United States? A Multiple Indicator Assessment", The American Journal of Sociology, 105.

[27] Putnam, R. D. (1995). "Bowling Alone: America's Declining Social Capital," Journal of Democracy, 6. Rezaei F, Yaseri M, Jahangiri nejat S. [Social Capital Examination in Jahrom University of Medical

[28] Sciences 2014]. JRUMS. 2015;15:295-306.

[29] Salehi Amiri R, Babashams A. [Measuring social capital among students]. GCM 2015;9(23):4759.

[30] Tashakor Z, Moeni M. [Looking at social capital and development]. SWQ. 2002;1(4):4-25. 